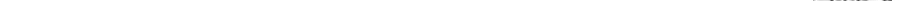





\title{
Aventuras de um índio
}

\author{
Justino Sarmento Rezende
}

\section{"Antigamente os brancos é que iam evangelizar os índios e agora, os índios vêm evangelizar os brancos!"}

Em agosto de 1997, eu cheguei à cidade de São Paulo. Os meus superiores proporcionaram-me um tempo para os estudos, Curso de Missiologia, com duração de dois anos, na Pontifícia Faculdade de Teologia Nossa Senhora da Assunção. Como sou salesiano fiquei morando na comunidade salesiana, no bairro da Mooca.

O diretor da comunidade, aos sábados celebrava a missa para a comunidade das irmãs (freiras) em um Hospital bem conhecido da Cidade. Um dia em que não pôde celebrar a missa para as irmãs, pediu que eu fosse em seu lugar. Como sei que um hóspede precisa ajudar naquilo que o dono da casa pede, acabei me dispondo. Outro padre da comunidade ouvindo o convite do diretor e minha disposição aconselhou-me a ir, porque iria gostar.

O diretor, então me disse:

- Alguém virá buscá-lo, no sábado por volta das 17h30.

Eu não conhecia o hospital nem as irmãs. Fiquei na expectativa sobre o que iria acontecer. Estava com curiosidades, mas ao mesmo tempo, com medo. Lugar desconhecido sempre me causa medo, pois não consigo imaginar quem irei encontrar. Daquela vez não foi diferente. Ainda mais que eu tinha trabalhado meus três anos de padre só entre os indígenas, isso me causava certa insegurança.

Chegou o dia de missa. Um funcionário do hospital foi me buscar no Colégio onde eu morava. Eu fui com receio, mas cheio de zelo pela missão. Eu fui pensando comigo: eu chego lá, celebro a missa e pronto!

Chegando ao Hospital caminhamos até encontrar a irmã responsável pela sacristia. Ela me cumprimentou e conduziu-

autor é indígena da etnia Tuyuka, nascido (1961) na aldeia Onça-lgarapé, na região do alto Rio NegroAmazonas. É sacerdote (1994) da Sociedade de São Francisco de Sales

(Salesianos). É aluno (2005) do Programa de Mestrado em Educação [Linha 3: Diversidade cultural e educação indígena] da Universidade Católica Dom Bosco (UCDB), Campo Grande-MS. justinosdb@yahoo.com.br 
me para a sacristia. Acontece que para chegar à sacristia tinha que passar por dentro da capela. Quando eu passei pela capela eu vi muitas irmãs e alguns funcionários do hospital. Nesta passagem ouvi alguns barulhos e comentários, dizendo: "ele é índio!, é índio!"... Ao ouvir estes comentários eu perguntei para a irmã sacristã, disfarçadamente: "será que as irmãs não vão ficar chateadas, porque o outro padre não veio?" Ela me respondeu: "Não se preocupe, padre. O pessoal vai gostar!" Fiquei com receio de celebrar a missa, mas como já estava ali, tive que celebrar.

Quando saí da sacristia e me dirigi ao altar, os comentários continuavam. Uma das irmãs não conseguiu controlar o seu espanto, admiração... Ela falou bem alto para outra irmã: "ele é índio, irmã!" A outra irmã afirmou: "É verdade, é índio! Está vendo? Antigamente os brancos é que iam evangelizar os índios e agora, os índios vêm evangelizar os brancos!" Ao ouvir isso, antes de iniciar o rito de missa, eu me apresentei. Eu disse que eu estava chegando do Amazonas e que eu era indígena Tuyuka. Pedi que não se escandalizassem com isso, pois eu iria celebrar somente aquela missa. Eu estava ali por motivo da viagem do diretor. A minha preocupação, quando se espantam com a minha presença é com a possibilidade do pessoal perder a fé em Jesus Cristo por causa de mim, isto é, se, o meu ser índio e ser padre não ajuda na fé do povo não-índio, eu me sinto culpado.

Por outro lado, acredito que todo terreno desconhecido causa medo, suspeita, reação... O meu ser índio é um terreno estranho e que amedronta o não-índio. $\mathrm{O}$ meu ser padre parece despertar certo respeito... Porém, depois que se conhece surge uma nova relação entre as pessoas. A partir daí, o índio não é tão ruim, não é tão assustador..., é bom ou como dizem alguns: 'ele é índio, mas é bom!'. As reações são tão numerosas quantas são as pessoas.

Assim como para estas irmãs o fato de um índio ser padre mexe com a mentalidade já estruturada sobre o índio e o padre. Difícil é conjugar índio e padre. Historicamente foi assim e muito pior! Conhecendo um pouco a história da colonização e evangelização dos povos destas terras eu venho mantendo contato com as diversas visões que os povos colonizadores têm com relação aos povos indígenas. Por muito tempo, os índios eram vistos como animais irracionais e, por isso mesmo, sem alma. Ainda estas idéias estão presentes nas representações de povos ditos "brancos", independente de ser um leigo, padre, irmã.

Diante de um fato como este, eu fico pensando comigo mesmo: a história que foi ensinada para eles é esta! Esta mesma história foi ensinada 
aos indígenas. O fato de eu ser indígena padre não vai modificar toda a história de séculos passados. Eu posso contribuir para que, a partir de mim, a partir do lugar onde atuo, a partir das pessoas com as quais eu convivo gerar uma convivência diferente do que eles criaram em suas mentalidades e mostrar como um indígena pode contribuir para que uma comunidade se enriqueça com os valores indígenas.

Este fato me fez refletir a respeito dos avanços na compreensão do que sejam os povos indígenas. Em nível interno da Igreja Católica, por exemplo, entre o momento em que o índio era visto como ser sem alma (não-gente) e aquele que começa a ser admitido ao sacerdócio há uma grande distância, um avanço considerável.

As confrontações ideológicas político-religiosas vão continuar existindo, enquanto existirem os povos indígenas e não-indígenas. Acredito que o trabalho de desestabilizar essas ideologias é um trabalho que deve ser assumido pelos próprios indígenas pelas formas diferentes de interpretar e criar suas histórias e histórias de outros povos.

As visões estereotipadas dos indígenas estarão presentes na sociedade e também, entre os povos indígenas sobre eles próprios. A desconstrução destes estereótipos é um trabalho diário. Se antes, o indígena só poderia ser evangelizado, hoje ele pode ser evangelizador. O não-índio e o índio podem ser evangelizados e serem evangelizadores. $O$ trabalho de evangelizar não é específico de um povo não-indígena.

\section{“Eu não confio nos índios!"}

Em 1999 eu estava em São Paulo. Neste ano aconteceu o Congresso Missionário Latino Americano na cidade do Paraná, na Argentina. E, a pedido dos meus superiores de Manaus eu fui participar deste Congresso.

$\mathrm{Na}$ data marcada para embarcar para a Argentina, eu estava no aeroporto internacional de Guarulhos. Enquanto eu andava na sala de espera, chegou outro colega padre que fazia o mesmo curso comigo. Este padre é negro. Era muito amigo meu. Ele também estava indo para o Congresso. Assim que ele me viu, perguntou: "Justino, você também vai ao Congresso?" Eu disse: "Estou viajando, sim!". Ele disse: “Que bom!" $\mathrm{E}$, logo pediu licença e saiu dizendo que estava acompanhando o seu Bispo.

Quando ele disse isso eu brinquei com ele: "Você anda com esse pessoal?" Mas ele achou graça e foi embora. 
Eu continuei andando por lá e vi que muitos padres, bispos, freiras e leigos chegavam. Era fácil de conhecer quem eram padres, bispos e freiras. Nestes momentos, todos eles se enfeitam com os seus adornos. Uns por convicção e outros para serem/terem destaques e privilégios. Os leigos que iam ao Congresso, também, andavam em grupos vestindo blusas com o símbolo do Congresso, com os distintivos brasileiros. Neste momento fazem de tudo para serem diferentes. E, muitos deles perguntavam: "você, também está indo? Onde está o seu distintivo?" Eu ficava na minha. Ao ouvir suas preocupações e provocações, eu só fazia sorrir.

Eu ficava andando sozinho. Como é o meu jeito. Mas ficava olhando todas aquelas manifestações eclesiais. Como eu estava imbuído de temas de história da evangelização que eram oferecidas no curso de Missiologia, eu ficava pensando mal deles: vocês prejudicaram os povos indígenas, destruíram suas culturas, e agora ficam fazendo essas festas... Estes tipos de pensamentos andavam comigo.

Enquanto eu olhava com o meu olhar de índio todo aquele movimento, o meu colega padre (negro) vinha voltando e veio em minha direção. Ele me disse: "Justino, vamos comigo que eu quero apresentar o meu bispo!" Eu, geralmente não gosto de ficar muito perto deste pessoal, pois eu sei que alguns deles são muito orgulhosos. Porém, aceitei o convite do meu colega, fui com ele. Chegamos perto do bispo. O padre disse: "Dom [...], este é padre Justino. Ele é do Amazonas. Ele é índio!" Quando ele falou isso, o bispo olhou para mim e disse: "Ele é padre? Eu não confio nos índios!" Ao ouvir isso, fiquei sem jeito. Não sabia se o cumprimentava ou fazia alguma coisa diferente. Esta atitude marcou-me profundamente na minha vida. Aumentaram mais, ainda, motivos para não ficar perto deles.

Diversos pensamentos vinham na minha cabeça. Vontade de desistir da viagem. Não acreditar nas atitudes dos bispos. Não acreditar em suas pregações... Tais atitudes me afastam cada vez mais da pessoa do bispo e suas celebrações. Mesmo aqueles bispos que são considerados muito bons, para mim não são bons. Penso que são bons para com aqueles que eles gostam.

Fato como este me deixou muita desconfiança. A Igreja que prega, respeito, inclusão, reconhecimento de diversos povos, prega que somos todos irmãos... E, os seus representantes assumem tais atitudes.

Embora pensasse em tudo isso, pensava em mim, todo o processo histórico dos povos indígenas, a evangelização que aconteceu e a minha presença neste processo de evangelização. Pensava comigo: eu posso contribuir com alguma coisa para que algo mude. 
Ao longo dos anos eu fui pensando que o bispo antes de ser padre/ bispo é um ser humano. Aquele bispo que me falou daquela forma era um homem "branco". Ele carrega consigo todas as visões sobre os povos indígenas. A sua família, a sua formação construiu nele aquela forma de ver o índio.

O fato de ele ser bispo não lhe modificou a visão estereotipada do índio. Embora ele pregue respeito pelos "irmãos índios", não tem condições de estar à frente de um índio, um ser diferente. A expressão que ele usou foi coerente com aquilo que pensa sobre o índio. Ele não estava errado ao dizer que não acreditava no índio.

Naquele momento, eu não era visto como padre, irmão no sacerdócio, mas fui visto como índio. Da mesma forma como eu disse dele, eu, antes de ser padre, eu sou índio. As pessoas sempre me verão como índio e em alguns momentos como padre. O meu "ser índio" traz consigo muitos estereótipos criados e recriados.

Hoje eu sei que todas estas visões estereotipadas são construções históricas, de relações de poder... A história da Igreja é construção histórica, relações de poder, de domínio... Ela, também construiu e reforçou a visão histórica da figura do índio: preguiçoso, irresponsável, não confiável... Quando um índio se torna padre leva consigo todos estes pré-conceitos para dentro da instituição. A instituição eclesial como só era formada por "brancos", quando aparece um índio padre, fica assustada, desestabiliza-se, desconfia...

O fato de os índios se tornarem padres, aqui no Brasil é um acontecimento muito recente. Os primeiros padres indígenas estão buscando se situar como podem. Aprendendo a dialogar, negociar, criando novas atitudes... O olhar de desconfiança de padres "brancos", principalmente dos mais velhos é muito presente. Às vezes, dá sensação que nós índios estamos invadindo a propriedade privada, o espaço que era só deles, "brancos".

Esta sensação se confirma se olharmos para a história indígena. Este tipo de sacerdócio da igreja não existe nas culturas indígenas. Está existindo agora com a evangelização. Com certeza deve criar ciúmes para os herdeiros históricos deste sacerdócio.

Imaginemos que um "branco" queira tornar um pajé, xamã, mestre de danças, nós não o veríamos com bons olhos. Mesmo que ele aprendesse tudo e fizesse tudo como é para fazer, ainda assim, funcionaria certa rejeição pelo fato de ele não ser membro do grupo herdeiro de tais práticas! 


\section{“Mamãe, ele é padre? Por que fala em tukano?"}

O Iauaretê é o nome de uma localidade, também o nome de um Distrito do Município de São Gabriel da Cachoeira-AM. Nesta localidade vivem vários povos indígenas: Tariano, Wanano, Desano, Piratapuia, Tuyuka, Arapaso, Hupda, Tukano e outros. Também, moram alguns não-indígenas, militares, agentes de saúde, correio... Atualmente habitam aproximadamente cinco mil habitantes, organizados em dez vilas (comunidades). Nos meus primeiros anos de padre eu trabalhei naquela missão salesiana (1994-1996).

Eu sou indígena Tuyuka. Como a língua mais falada em Iauaretê é Tukano eu a usava direto. Coloquei na minha cabeça que para fazer o povo compreender a mensagem eu tinha que falar em tukano. Assim eu tenho feito nas conversas com os indígenas que vivem naquele distrito.

Também na missa, eu uso a língua tukano. O fato de eu usar esta língua facilita a compreensão da mensagem transmitida. Os mais idosos gostam muito. Também muitos jovens gostam. Há grupos que não gostam muito.

Aqueles que não gostam que fale em tukano nas missas acham que o bom padre tem fazer a pregação na língua portuguesa. A história missionária levou a criar esta imagem/mentalidade. Maioria dos missionários como não aprenderam língua tukano falavam somente a língua portuguesa. Talvez, por isso, muitos indígenas entenderam que o português fazia parte do ritual da missa. Por muito tempo foi assim. E, continua assim até hoje.

Há poucos anos atrás começaram a aparecer os índios padres, desta região, a partir de 1992. Eu sou um deles. Nós começamos a falar a língua tukano nas missas.

Olhando para as reações do povo surgem alguns questionamentos: será que a língua tukano usada nas missas diminui a fé do povo indígena? Será que a língua portuguesa ajuda mais a fé do povo indígena? Muitas vezes dá impressão que sim. Uma autêntica pregação tem que ser feita em português. São realidades que estão presentes no meio do povo indígena.

É nesse contexto que surge esta dúvida existencial de uma criança. Penso que esta dúvida e questionamento desta criança são reflexos daquilo que muitas outras crianças pensam. Não somente as crianças, mas jovens e os adultos.

A mãe da criança contava para mim sobre o diálogo entre ela e seu filhinho de quatro anos durante a missa que eu estava presidindo no dia de domingo. 
A mãe da criança disse que na hora que eu comecei a missa, a criança ficou observando atentamente e por muito tempo. A mãe disse mais: a criança olhava para mim (padre), olhava para as pessoas e olhava para a mãe. Esta atitude era como se ela dissesse: será que eles estão vendo o que eu estou vendo? Ou eles não estão vendo?

A mãe da criança disse que na hora em que todos se sentaram para ouvir a minha homilia, a criança continuou olhando para mim (padre) e depois perguntou para a mãe: mamãe, ele é padre? A mãe respondeu: Sim, meu filho. Ele é padre! A criança perguntou para a mãe: Por que ele está falando em tukano? A mãe respondeu: Porque ele é nosso parente. Por isso, ele fala em tukano!

A presença missionária foi criando no imaginário do povo um estilo de ser padre. Quando surge índio padre, parente deles, falando a mesma língua que eles falam, desestrutura o imaginário construído há várias décadas. A língua tukano falada nas missas diminui aquele mistério que existia. Fazia parte do mistério da missa, não entender tudo, só o padre entendia tudo. A língua tukano falada na missa acaba revelando o que estava escondido.

Penso que para os povos indígenas que estão acostumados com rituais, danças... que usam línguas muito antigas e, por isso, incompreensíveis, uma missa com linguagens incompreensíveis não faz grandes diferenças. O importante é que os agentes dos rituais saibam falar aquelas línguas, pouco se importam se o restante dos participantes estão entendendo ou não. São ritos e suas linguagens não precisam ser entendidas, mas repetidas.

Para muitas pessoas o espaço para falar a língua tukano é fora da igreja, fora da celebração... Digamos que não é língua 'religiosa'. A língua para falar com Deus é língua portuguesa. Deus entende e atende na língua portuguesa. Deus não atende pela língua indígena. Dentro deste contexto que a Igreja, hoje, está procurando trabalhar a questão da inculturação do evangelho: falar de Deus na sua própria língua, louvar a Deus na sua própria língua e usar os símbolos indígenas nas celebrações litúrgicas etc. Mas isso não avança, pois a outra forma de celebrar influenciou demais a vida dos indígenas da região.

A resistência ao surgimento de outro estilo de evangelizar só pode ser compreendida a partir da compreensão da construção histórica deste povo. Por um longo tempo os povos indígenas foram ensinados assim. 


\section{"Nós estamos sempre combatendo os missionários e vocês se tornam padres?"}

No ano de 2002 eu estava vivendo em Manaus. Naquele ano a Fundação Estadual de Política Indigenista (FEPI-AM) organizou um evento chamado I Conferência dos Pajés do Amazonas. Como no grupo da organização havia alguns colegas, convidaram-me para participar do evento e eu aceitei.

Realmente o nome da Conferência chamava-me muita atenção. No tempo de minha infância eu havia conhecido e convivido com os pajés, avôs meus. Nesta convivência eu vi e ouvi muitas coisas de pajé e sobre o pajé. Pensei comigo: já que os meus avôs não existem mais, eu não tenho possibilidade de conhecer depois de adulto, eu vou conhecer os pajés e conversar com alguns deles.

Eu fui participar, mas fui com medo. Os meus avôs haviam me ensinado que quando têm muitos pajés, principalmente, quando são de diferentes etnias, teria que ter medo ou pelo menos estar protegido das forças negativas que possam sair deles. Diziam mais, o pior que sempre sobra para quem é mais fraco. O mais fraco neste caso é aquele que não é pajé.

Como até hoje eu uso o benzimento de meus parentes para a proteção da minha vida, eu usei e fui.

No dia da abertura fiz questão de chegar atrasado por opção, pois eu calculei que alguns sábios no início já deveriam ter feito o benzimento para apaziguar os males que daí pudesse sair.

Quando eu cheguei já estavam presentes indígenas de várias etnias. Vi alguns indígenas conversando no meio de seus grupos. No meio encontrei um pajé Tuyuka, da minha etnia. Entre os pajés reconhecidos, havia, também, pajés de 'nome', oportunistas.

Estes últimos andam pelas cidades enganando a boa fé do povo "branco". Como eu já os conheço, quando me viram ficaram se disfarçando. Mas como andavam cheios de enfeites as atenções das câmeras voltavam-se mais para eles do que para aqueles que eram realmente pajés.

Além de vários indígenas, homens e mulheres, havia muitos representantes de instituições governamentais, das ONGs e representantes de organizações indígenas. Eles ocupavam mais espaços e apareciam mais que os próprios pajés. Não duvido muito que eles que tenham aproveitado o nome da Conferência para aparecerem e propagarem as suas idéias. 
Quem sabe se eles se consideram pajés?

Foi no meio deste movimento todo que eu encontrei alguns conhecidos indígenas. Num certo momento um deles me chamou e disse: "Padre, eu vou apresentar uma pessoa para você. Ela é mulher. É indígena e é advogada! Ela é bonita e não vai ficar doido por ela!" Ele falava assim, pois sempre foi bagunceiro.

Eu fui com ele e chegamos perto de uma moça elegante e alta, ele disse: “[...], eu vou te apresentar um índio Tuyuka, ele é nosso parente. Ele é padre!" Ao ouvir isso ela ficou enfurecida e esqueceu de me cumprimentar e eu, também fiquei parado sem saber o que fazer. Ela disse assim: "Nós estamos sempre combatendo os missionários e vocês se tornam padres? Não sabem que eles que destruíram as nossas culturas?"

$\mathrm{Eu}$, realmente fiquei sem saber o que dizer e fiquei achando graça. Mas logo depois, eu também já fiquei sério e bravo. Eu respondi para ela: "Ainda, bem que eu sou padre. Se eu não fosse padre você não teria com quem brigar!" Ouvindo isto ela ficou sem saber o que me dizer. Somente depois, ela me cumprimentou.

Eu não fiquei com raiva dela, pois ela como indígena militante dentro do Movimento Indígena possui a sua visão sobre a história dos missionários no Brasil e como eles trataram os povos indígenas. Eu não quis discutir com ela sobre isso.

Mas o que eu pensei comigo foi o fato de não me conhecer nada e me considerar como inimigo dos povos indígenas. Também tenho engajamento no Movimento Indígena de forma semelhante ao dela. Talvez mais do que ela. Eu também sou índio e sou padre.

Mas ao longo do Congresso ficamos nos conhecendo melhor. Com certeza as nossas visões já são diferentes das daquele primeiro momento.

O que fica claro por este fato é o lugar de onde você está falando para a outra pessoa. Naquele momento ela, indígena, não me viu como índio, mas viu como padre, membro de uma instituição que ao longo de cinco séculos foi estabelecendo diversos tipos de relações com os povos indígenas. Eu conheço as mesmas histórias que ela estudou. Também fico com raiva, quando estudo tais situações.

A desconstrução desta história é a nova maneira de ver esta história e a pessoa do índio. $\mathrm{O}$ fato de eu ser índio padre e estar engajado no Movimento Indígena para ela não contava. Ela mostrou a visão estereotipada, historicamente construída na mentalidade indígena: todo padre é contra os índios, é destruidor das culturas... Se eu fosse olhá-la somente 
como advogada, não a veria como defensora dos povos indígenas, pois muitos advogados advogam em favor dos "brancos" e contra os povos indígenas.

A construção de novas visões com relação a muitas realidades que eram dos "brancos", e, assumidas pelos índios, hoje, passará por um grande repensamento, ressignificação...

\section{“Você não pode fazer o povo dar risadas na missa"}

Eu sou índio Tuyuka. Os Tuyuka, geralmente são muito brincalhões. Se você chegar a uma aldeia indígena e se estiver reunido em grupo, você ouve de longe as gargalhadas. O Tuyuka é um povo muito alegre. Gosta de brincar com as pessoas. Gosta de colocar apelidos nas pessoas. Qualquer coisa, a sua fala, o seu jeito, a sua boca, o seu nariz..., torna-se motivo de brincadeiras.

Eu me tornei padre em 1994. Só que estas características culturais tuyuka continuam na minha pessoa. O sacerdócio que eu recebi não lavou a minha cultura presente dentro de mim. A cultura cristã foi acrescentada à cultura tuyuka, a cultura sacerdotal foi acrescentada à cultura tuyuka. Assim sendo eu acabo sendo muitas culturas, ao mesmo tempo.

Quando celebro missas com os povos indígenas, principalmente, falando na língua tukano eu conto muitas situações, fatos, histórias interessantes que ajudam o povo a compreender a mensagem que está sendo transmitida. Como as pessoas estão entendendo bem, entram nas histórias, e, alguns momentos dão risadas e muitas risadas.

Dentro da própria homilia fazendo a aplicação da Palavra de Deus à vida indígena eu conto vários fatos da vida indígena que leva ao povo a palavra para dentro de suas vidas. E, dão risadas, pois estão entendendo o que está sendo dito. Segundo a filosofia indígena (Tuyuka) se estão dando risadas ou conversando na hora que eu estou falando, é sinal que estão entendendo o que eu estou dizendo. O silêncio nem sempre é sinal da compreensão.

Na missão salesiana de Iauaretê, onde eu trabalhei nos primeiros anos de sacerdócio, quando eu presidia a missa sempre havia outro padre concelebrando comigo. Eu percebia que quando o povo dava risadas ele olhava para mim, olhava para o povo e olhava para os coroinhas. E todos eles estavam dando risadas. Ele não entendia o que estava sendo falado porque não aprendeu a língua indígena. Talvez por isso, ficava 
desconfiado de tudo isso. Pode ser que algumas vezes ele achava que estivéssemos falando dele. Mas, às vezes eu falava dele, mas dizia o nome.

$\mathrm{O}$ índio padre tem seu estilo próprio de presidir as missas. Mesmo que as normas litúrgicas sejam rígidas sempre se criam brechas para sinais culturais. Acredito que assim enriquece a liturgia celebrada com os indígenas. Também, é um desafio para o padre não-índio aprender a língua local, para que possa entender pelo menos o que se está falando. $\mathrm{O}$ certo seria aprender a falar, mas muitos acham que não precisam. Cada um pensa da forma que quer.

Algumas vezes eu via que depois da missa, o padre perguntava para os coroinhas sobre aquilo que eu estava falando e por que o povo dava risadas. Na maioria das vezes os coroinhas indígenas só achavam graça e não explicavam. Outras vezes explicavam para ele o motivo. $\mathrm{O}$ padre parecia não acreditar muito. Quando não entende uma língua tudo fica complicado.

Até que um dia ele me chamou e disse: "Padre Justino, as suas missas são bem animadas. $\mathrm{O}$ povo gosta muito. $\mathrm{O}$ povo entende bem $\mathrm{o}$ que você fala". O que eu quero dizer para você é: "Você não pode fazer o povo dar risadas na missa! A missa não é para isso!"

Eu ouvi com muita atenção a observação dele, mas não consegui seguir o seu conselho. O sacerdócio e as celebrações precisam ser enriquecidos pelos valores culturais.

Nos meus primeiros três anos de sacerdócio fui muito levado pela empolgação. Muitas questões que foram surgindo ao longo da prática ficam sem respostas. Eu sabia que a partir de um índio padre a prática da Igreja teria que assumir um novo rosto. Diante desta empolgação estavam padres de longos anos e os povos de longos anos.

Por isso, que o Curso de Missiologia, com atenção especial para a evangelização inculturada (inculturação) foi uma ajuda para compreender que a evangelização entre as culturas indígenas, precisa partir das culturas. Precisa passar pela descolonização das práticas evangelizadoras.

Eu vejo que também nas celebrações de missas que já realizei nas cidades o povo gosta e dá risadas. Eu penso que estas risadas, também fazem bem para algumas pessoas.

A celebração é momento de relações humanas, não de anti-humanismo. O sorriso, a risada ajuda o povo a se sentir bem. Fala-se que Deus é Deus da vida, por que ele é contra a risada? Deus é Deus da alegria! A Igreja precisa mostrar o seu rosto alegre. Um sorriso bem dado, uma risada dentro de uma celebração evangeliza mais do que muitos sermões sérios. 
Seja como for, a cultura da Igreja, a cultura litúrgica precisa encontrar-se com a cultura local (indígena).

\section{“Padre Justino, você está na profissão errada!"}

Nos anos de 2001-2003 eu estava trabalhando em uma paróquia na cidade de Manaus. Como a paróquia era grande, nos bairros populares funcionava grande número de pastorais, movimentos...

Ao longo destes anos eu priorizei a cataquese para o trabalho. Talvez por causa disso, algumas paróquias de Manaus convidavam-me para assessorar em suas assembléias de catequese.

No ano de 2003, como aquele que deveria assessorar não podia comparecer a coordenação arquidiocesana correu em busca de outros padres e como não encontraram nenhum padre disponível, recorreram a mim. Sempre sobrava para mim, quando os melhores não queriam assumir. Diante disso, eu chegava até dizer para mim e para as pessoas mais próximas: “outra vez, eu não irei!" Mas sempre acabava aceitando. Eu não sabia dizer não. Assim mais uma vez eu aceitei em assessorar a assembléia da catequese arquidiocesana. Estavam presentes representantes de muitas paróquias e áreas missionárias de Manaus. Pediram para eu trabalhar sobre a Catequese na Cidade e Deus ecológico. Eu me esforcei para preparar.

No dia da assembléia escolheram um lugar afastado da cidade e no meio de uma floresta. Eu gostei. Índio que não gostasse do mato não seria bom índio! Só o ambiente já era um grande recurso metodológico, pedagógico, catequético, ecológico. Só bastava colocar Deus no meio de tudo isso, pois o índio já estava lá (eu).

Estavam presentes aproximadamente trezentas pessoas. Para conseguir fazer com que eles ficassem ligados à exposição eu misturava os conteúdos dos temas propostos, histórias indígenas e fatos da vida das paróquias, principalmente na catequese. Os participantes ficavam ligados. Davam risadas, e achavam graça em muitos momentos. Assim ficava menos cansativo. Eles gostaram muito. Batiam palmas!

Chegamos ao final da primeira parte e fomos para o intervalo. Durante este tempo a assessora arquidiocesana me chamou e disse: "Padre Justino, você está na profissão errada, você era para ser palhaço! Fala com mais seriedade para os catequistas, pois nós não viemos aqui para brincar!". Eu aceitei a ordem da assessora. Voltando aos trabalhos 
eu falei para os catequistas que não iria mais adotar a metodologia da primeira parte, a pedido da assessora. Fui falando sério com eles. Depois de dez minutos um catequista levantou a mão e pediu a palavra. Eu dei a vez para ele. Ele disse: "Padre Justino dá para o senhor usar a metodologia da primeira parte?" Quando ele disse isso todos os catequistas gritaram: "é isso mesmo, é isso mesmo!" Tive que desobedecer a assessora!

Mas, no mesmo momento, a assessora arquidiocesana saiu. Eu não sei o que ela achou sobre isso, mas eu sei que não ficou.

\section{“Você pode ser muito bom na sua língua, mas em inglês você é péssimo!"}

Em 1980 eu chegava a Manaus. Antes de chegar a Manaus todo tempo eu estudei na missão salesiana de Pari-Cachoeira, na região do alto Rio Negro, Município de São Gabriel da Cachoeira-AM.

Sair daquele lugar e ir para a cidade de Manaus para mim aconteceu em meio a grandes angústias. Eu estava saindo pela primeira vez de junto de meus pais e da minha região. Estava indo para um lugar desconhecido, sem saber quem eu iria encontrar naquele novo lugar.

Viajar de avião já foi o primeiro choque. Chegando a Manaus encontrei outros jovens que vinham de outros lugares, e, entre eles alguns indígenas. Os meus colegas indígenas me animaram um pouco nos primeiros dias. Mas logo acostumei a conviver com os outros. Eu sabia falar muito pouco o português. Nos primeiros dias de aula, principalmente quando tinha que fazer alguma exposição de trabalho, o pouquinho de português que eu sabia, desaparecia.

Os seminaristas não-índios bagunçavam comigo. Em alguns momentos dava vontade de chorar e ir embora para casa. Como é que eu podia ir embora se não conseguia nem sair para as ruas da cidade? $\mathrm{O}$ jeito era ficar e aprender a nova língua.

Neste ano eu estava começando o $2^{\circ}$ Grau como se dizia naqueles anos, hoje, ensino médio. Comecei a ter muitas matérias novas que eu nunca imaginava que existia: biologia, física, química, latim, inglês, italiano... Eu ficava só olhando e não sabia como reagir. Eu estava perdido.

Chegou o dia que eu não queria que chegasse: dia de começar a aula de inglês. Eu me lembro muito bem como aconteceu. O professor era um padre norte-americano. Falava muito mal o português, mas era bom em inglês. Era a sua língua! 
Depois de apresentar-se e fazer a chamada de alunos, começou a perguntar quantos alunos já haviam tido aula de inglês no $1^{\circ}$ Grau. Muitos alunos levantaram. Somente os alunos indígenas não levantaram as mãos. Eu não levantei, nunca tinha ouvido falar que existia inglês em uma sala de aula. Depois o professor propôs um trabalho individual na sala de aula. A maioria aceitou e assim foi feito. Ele disse: "peguem uma folha de papel e escrevam alguma história em inglês".

A maioria dos alunos começou a escrever. Também, os índios que estavam lá, escreviam. Eu não sei o que escreveram, mas escreviam. Eu apenas observava os alunos escrevendo, olhava para o professor, olhava para as paredes, pensava na minha aldeia, na minha família. Eu, simplesmente fiquei parado e olhando.

Depois de um tempo eu pensei comigo: "eu vou tirar zero, pois eu não sei escrever em inglês!" Neste momento caiu uma idéia: escrever a história de cutia (animal) em língua tukano. Eu pensava comigo: eu não sei escrever em inglês, vou escrever na língua que eu falo e quero ver se ele vai entender. Assim eu fiz e entreguei.

Na aula seguinte, o professor chamava cada aluno e dizia a nota do trabalho. Muitos alunos foram elogiados. Eu ficava olhando para ver o que iria acontecer quando chegasse a minha vez. Depois que havia chamado todos os outros alunos, o professor parou e ficou olhando para os alunos e perguntou: "quem é o Justino aqui?" Eu estava sentado bem atrás. Eu levantei a mão e fui receber o trabalho. Ele me disse assim: "você pode ser muito bom na sua língua, mas em inglês você é péssimo! Como eu não entendi nada de sua língua, eu te dei nota sete (7)!"

Desta vez eu tive sorte. Esta cena me faz entender a dificuldade que temos em alguns espaços, quando não entendemos ou falamos uma língua. As nossas seguranças lingüísticas, culturais tornam-se frágeis.

\section{"Eu sou ruim para flechar?"}

Na época em que eu era criança (na década de 1960), na aldeia Onça-Igarapé havia muitos meninos de minha idade. Como meninos Tuyuka a nossa brincadeira baseava-se naquelas brincadeiras que mais tarde transformariam em instrumentos de trabalho: pescaria, pesca...

Nós brincávamos de pescar com cipós. A brincadeira funcionava assim: um ou mais meninos pegavam numa ponta e ficavam fora d'água. Outro grupo ficava em uma outra ponta, mas dentro do rio. Quem ficava fora d'água puxava, até à beira, os que estavam dentro d'água. Quem 
ficava fora d'água representava os pescadores e quem estava na água representavam os peixes. Mas ninguém cozinha!

Outra brincadeira era feita com arco e flecha. As nossas vítimas eram os sapinhos que ficam no fundo do rio e outros bichos que a gente encontrasse. Porém, a vítima preferida era o calango.

A nossa brincadeira era sempre em grupo. Em todas essas brincadeiras nós queríamos sempre disputar para ver quem era o melhor: melhor pescador, melhor flechador... Entre nós sempre havia meninos que eram bons em tudo. Havia outro grupo que sempre perdia. Eu era um deles.

Estávamos vivendo mais um dia de brincadeiras. Fomos tomar banho nas cachoeiras. Nós tomávamos banho por muitas horas, até o nosso corpo começar a tremer e os nossos olhos ficarem vermelhos. Saindo do banho já saíamos correndo para outras brincadeiras, por exemplo, quem chegava primeiro na aldeia. Depois íamos cercar os calangos. $\mathrm{Na}$ nossa aldeia havia bastante. Cercávamos o calango e ele se escondia entre as árvores, capinzal. Mas alguém sempre o enxergava. Aí começava a flechada. Mas eu quase sempre não acertava. Não é que não acertava, havia outros meninos que eram mais rápidos do que eu. Mais uma vez eu não acertei. Foi quando um menino disse para mim: você é muito ruim na flecha!

Eu sabia que eu era ruim no arco e flecha e o outro sempre me levaria vantagem. Mas eu fiquei com raiva naquele dia. Aí eu disse: Deixa-me ver se eu sou ruim na flecha. Dizendo isso, eu flechei na batata da perna.

Naquele momento ele quebrou a flecha e puxou para fora. Mas não me fez nada. Se ele quisesse poderia me acertar em qualquer outra parte do meu corpo. Mas eu fiquei com muito medo. Por alguns dias eu deixei de andar com eles, por vergonha e medo. Mas depois de alguns dias eles me chamaram. O nosso grupo estava novamente completo. Eu me arrependi de ter flechado o meu colega.

Recebido em 25 de junho de 2005.

Aprovado para publicação em 31 de julho de 2006. 
